searches. On the other hand, the professed physicist, interested in the properties of matter from a more general point of view, prefers to work on materials of a more tractable nature than those with which the geologist is concerned.

The memoir before us, the joint work of a geologist and an engineer, deals with the constants of elasticity of a number of crystalline rocks, and gives the results of a series of experiments made in the laboratories of McGill University at Montreal. The quantities investigated are among the prime desiderata of geological mechanics, being involved in the calculation of the velocity of propagation of earthquake shocks and in other important questions. The only data of this kind previously published seem to be open to serious criticism, and the contribution by Profs. Adams and Coker is specially opportune and welcome.

The authors describe the method employed and the precautions taken to ensure such accuracy as is possible. The rock is cut to the shape of a column 3 inches high and I inch in diameter, either square or circular in crosssection. The column is subjected to pressure applied perpendicularly upon its ends, and the resulting longitudinal compression and lateral extension are observed. In this way are obtained Young's modulus, E (the longitudinal stress divided by the longitudinal compression), and the ratio $(\mathrm{m})$ of longitudinal compression to lateral extension (i.e. the reciprocal of Poisson's ratio). The modulus of cubical compression (D) is then calculated from the relation

$$
\mathrm{D}=\frac{1}{3}\left(\frac{m}{m-2}\right) \mathrm{E} \text {, }
$$

and the modulus of shear $(\mathrm{C})$ from

$$
\mathrm{C}=\frac{1}{2}\left(\frac{m}{m+\mathrm{I}}\right) \mathrm{E} \text {. }
$$

From the theoretical point of view these equations do not seem to be fairly applicable to the case in hand. A crystalline rock is an aggregate of many crystals, each of which is anisotropic; and in the case of such a rock as granite the crystals belong to a number of distinct minerals, differing as regards their elastic constants. The argument that an average isotropic effect will result from the random orientation of a large number of anisotropic crystals is not quite convincing. Nevertheless, the results found are reasonable and consistent, and go far towards justifying the method adopted.

When the relation of strain to stress is plotted on a diagram, it is seen in every case that the progressive loading gives a curve not very different from a straight line, while the corresponding line for unloading is a curve lyins very near the other, and returning to the initial point. It follows that the rocks examined approximate nearly to perfect elasticity, and obey Hooke's law somewhat closely, and with small hysteresis, for pressures ranging up to $10,000 \mathrm{lb}$. or even $15,000 \mathrm{lb}$. to the square inch. Many of them compare favourably in these respects with cast iron. We quote some of the results obtained for the seventeen rocks examined. The figures are to be multiplied by $10^{11}$ to give the measure in C.G.S. units :-

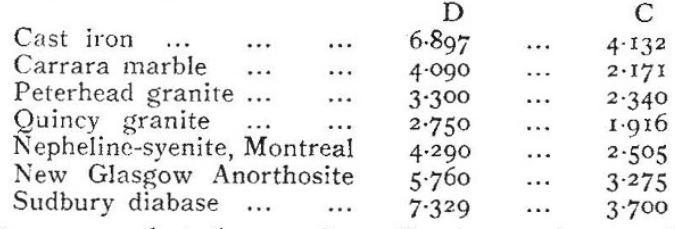

It appears that the granites offer less resistance, both to compression and to shearing, than the basic igneous rocks. The authors connect the greater compressibility of the granites with the presence of quartz, but the granites appear to be actually more compressible than that mineral. We should suppose rather that the alkali-felspars, which constitute the greater part of an ordinary granite, are notably more compressible than the ferro-magnesian silicates and lime-felspars; and this seems to be confirmed by the intermediate value found for the nepheline-syenite. ${ }^{1}$ The general character of the rocks which compose the bulk of the earth's crust is doubtless fairly represented by

1 The authors cite Vo:gt's value for the compressibility of quartz. The more accurate determination by Amagat gives $4^{.212}$ in terms of the unit adopted above. For the felspars there are no known data. the crystalline igneous rocks selected for investigation, and the average compressibility must lie between the highest and lowest values tabulated above. A simple average of all the igneous rocks examined gives a modulus of compressibility $4.374 \times 10^{11}$, which is slightly less than that for plate glass. In such an average the acid rocks are probably over-represented, and the value consequently too low.

A. H.

\section{CYANOGENESIS IN PLANTS AND THE CONSTITUTION OF PHASEOLUNATIN.}

SINCE 1900 a considerable number of plants yielding prussic acid have been investigated in the Scientific and Technical Department of the Imperial Institute. Among these are Lotus arabicus, a plant which grows commonly along the valley of the Nile; Sorghum vulgare, widely cultivated as a cereal in tropical countries; the Lima bean (Phaseolus lunatus); common flax; and cassava (Manihot utilissima). The source of prussic acid in each of these cases has been proved to be a glucoside, which in the presence of water is decomposed by an enzyme, also occurring in the plant, yielding prussic acid, glucose, and a third neutral substance. Three of these glucosides have been fully studied by Prof. Dunstan and Dr. Henry. Lotusin, $\mathrm{C}_{28} \mathrm{H}_{31} \mathrm{O}_{16} \mathrm{~N}$, from Lotus arabicus, is comparatively complex in structure, and is the lotoflavin ether of maltose cyanohydrin, lotoflavin being a yellow colouring matter isomeric with fisetin and luteolin, and belonging, like these, to the quercetin group of dyes. Dhurrin, $\mathrm{C}_{14} \mathrm{H}_{17} \mathrm{O}_{7} \mathrm{~N}$, from Sorghum vulgare, is a dextrose ether of parahydroxybenzaldehyde cyanohydrin. Phaseolunatin, $\mathrm{C}_{20} \mathrm{H}_{17} \mathrm{O}_{6} \mathrm{~N}$, which occurs in the Lima bean, flax, and cassava, has been shown to be a dextrose ether of acetone cyanohydrin (Phil. Trans., I901, B, 515; 1902, A, 399 Proc. Roy. Soc., 1903, 1xxii., 285 ; 1906, 1xxviii., 145 and I52; British Association Reports, 1906, and Ann. Chim. Phys., 1907, [viii.], x., I18).

In a paper communicated to the meeting of the Royal Society held on February 28 , the same authors, in conjunction with Dr. Auld, gave the results of some further investigations carried out with the object of determining the nature of the dextrose residue present in phaseolunatin.

Fischer and others have shown that glucosides are divisible into two classes, derived respectively from the $\alpha$ and $\beta$ forms of the hexoses, and that the glucosidolytic enzymes which occur in plants also belong to two groups. the one, typically represented by maltase, being capable of decomposing a-glucosides, and the other, of which emulsin is the best known, having the power of hydrolysing $\beta$-glucosides. From the results of the examination of the sugar initially produced when phaseolunatin is hydrolysed by the enzyme, which orcurs in association with it in the Lima bean, it is clear that this is $\alpha$-dextrose, and, therefore, that phaseolunatin is the $a$-dextrose ether of acetone cyanohydrin. It is the first naturally occurring glucoside of this type so far known.

This conclusion has rendered necessary a further investigation of the enzymes, which occur with phaseolunatin in the Lima bean, the flax plant, and cassava. The mixture of enzymes, prepared in the usual manner from the Lima bean, decomposes amygdalin and salicin, and may therefore be assumed to contain emulsin. The latter, prepared from sweet almonds, has, however, no action on phaseolunatin, and this is in harmony with the constitution now assigned to the latter glucoside, since the emulsin of almonds has been shown to hydrolyse only glucosides containing $\beta$-sugar residues.

It has now been found that the Lima bean contains, in addition to emulsin, a second enzyme, which is of the maltase type, and that the decomposition of phaseolunatin, which takes place when the beans are ground up in water, is due to the action of the maltas -like enzyme. The maltase of yeast is also capable of decomposing phaseolunatin, so that the enzyme which occurs in the Lima bean appears to be of the same type as the maltase present in yeast.

The mixtures of enzymes occurring in association with phaseolunatin in the flax plant and in cassava have also been investigated and found to behave in the same manner as the mixture of enzymes prepared from the Lima bean.

NO. I 949, VOL. 75$]$ 